\title{
АСКЕТИКА КАК ПРЕДМЕТ ФИЛОСОФСКОГО ОСМЫСЛЕНИЯ
}

\section{В.Ю. Куценко}

Рефлексия аскетического опыта - неотъемлемая составляющая любой религиозной традиции. Но особенностью ХХ века стало то, что обсуждение проблем «внутреннего делания» вышло за рамки богословского дискурса и стало актуальной темой философии. Современная философия все больше интересуется аскетикой в связи с интересом к практикам субъективации, в рамках которых осуществляется конструирование субъектности. Понятие «субъективация» в неклассических философских подходах находится во взаимосвязи с целым спектром насыщенных смыслами понятий «забота о себе», «практики себя», «духовные практики», «искусство жизни» и т.п. Как поясняет Жиль Делез, «субъективация - это производство модусов существования или стилей жизни [...] то, что Ницше называл изобретением новых жизненных возможностей» $[6$, с. 124].

От тотального осуждения аскетизма как негуманного явления в классическом гуманизме и философии французского Просвещения философы перешли к его доскональному изучению в связи с проблемой свободы. Современный православный богослов митрополит Каллист (Уэр) ссылается в данном вопросе на Н.А. Бердяева, который определял аскезу как «концентрацию внутренних сил и управление собой», а цель аскетизма видел в освобождении человеческой личности [9]. В философии М. Фуко аскеза («философская аскеза», берущая начало от пифагорейства) соотносится с «практикой себя»: «Аскеза [...] конституирует - в этом и состоит ее цель - субъекта, делает его субъектом истинного говорения» [14, с. 402]. Современные комментаторы поздней философии Фуко выделяют центральный тезис его 
теории - «тезис о том, что именно взаимоотношение двух принципов, познания себя и заботы о себе, является ключевой характеристикой, определяющей состояние человека, общества и культуры в каждую эпоху» [15, с. 512$]$.

Сегодня утверждается мысль, что необходимо говорить о разных моделях аскетического преобразования мира, что осмысление аскетики как практики духовной деятельности человека требует сравнения аскетических систем $[1 ; 5 ; 7 ; 10]$. Отсюда встает актуальная задача создания продуманной методологии такого сравнения.

В данной статье преследуется цель проанализировать и сопоставить опыты философской интерпретации основных понятий аскетики. Это необходимо для того, чтобы выяснить механизмы, с помощью которых формируется субъективность - ядро той или иной конкретной культуры. Учитывая обозначенный исследовательский интерес, следует остановиться на интерпретациях аскетики М. Вебера, Д. Зильбермана, М.Фуко, С. Хоружего. Все они отправной точкой и центром исследования имеют современного человека, его цели, ценности и идеалы. Теории указанных авторов необходимо проанализировать, чтобы проследить динамику осмысления интересующей нас темы. Мы остановимся на веберовском подходе, развитом в работах Зильбермана. Осуществленный Вебером анализ протестантской этики сегодня понимается как одна из первых попыток рассмотрения влияния религиозных факторов на ход истории. Аскеза в миру - одна из центральных тем мыслителя. Эффект Вебера и его влияние на ход развития социально-гуманитарного знания огромен. Он предложил определенную стратегию исследования такой сложной «материи» как духовность. Важно продолжить его мысль о том, как воплотились в жизнь сотериологические установки разных религий, какие стили жизни они породили.

В работе «Протестантская этика и дух капитализма» Вебер ставит вопрос и проблему: показать механизм влияния религиозного сознания на социально-экономические отношения. Как социолог Вебер предложил методику поиска взаимосвязи между духовными и культурными факторами с факторами социальными.

Для начала поставим вопрос, на какой образ человека ориентируется Вебер? Во главу угла поставлен человек сознательный (осмысляющий, ответственный), действующий, рациональный, социальный.

По мнению Вебера, в основе религии спасения, распространенной на Западе, лежит именно аскетизм, который и позволяет утвердить рациональное отношение к миру. В принципе, в основание западной со- 
циологии религии конца XIX - первой половины XX вв., ярким представителем которой является Вебер, заложен тезис, что общества развиваются по одинаковому сценарию, модернизация всегда имеет примерно схожие следствия как для общества в целом, так и для религии, в частности [13, с. 135-148]. П.П. Гайденко и Ю.Н. Давыдов отмечают, что в своем анализе религиозной этики Вебер не меняет методологические средства анализа:

\begin{abstract}
Эталоном для сравнения у него здесь, так же как и в других разделах его социологии, остается целерациональное действие, а его наиболее чистым вариантом является действие экономическое. Поэтому установление типа связи религии именно с хозяйственной этикой остается для Вебера по-прежнему важнейшим средством анализа как самой религии, так и отношения ее к другим социальным образованиям праву, государству, науке, искусству и т.д. [4, с. 99].
\end{abstract}

Как мыслитель Вебер принадлежит к интеллектуальной традиции Просвещения с ее изначальным европоцентризмом. Он неуклонно подчеркивал уникальность ценностного комплекса, укорененного в протестантской этике, и социальных условий, способствовавших его распространению в обществе. Этим Вебер подтверждал несомненную для него цивилизационную уникальность Запада.

Веберовский подход отличается тем, что при классификации типов религиозного поведения важнейшим является сравнение, производимое на основании степени рационализации религиозно-этических установок. Сравнение производится Вебером на основании понимания смысла совершаемых действий, с учетом мотивов действующих индивидов.

Вебер интерпретирует кальвинистское учение об индивидуальном спасении как основанное на строгой рациональной этике. Общие ее рамки задаются «религией спасения», которая развивается в двух главных руслах: мистического созерцания и активного религиознонравственного действия. Второе русло, по Веберу, есть русло аскезы, которая, в свою очередь, имеет ряд форм. В «Теории ступеней и направлений религиозного неприятия мира» он выделяет две установки мироотношения: отвержение мира - преобразование (освоение, подчинение) мира:

Уже на пороге своего появления аскетизм выступает в двойственном облике: как отречение от мира, с одной стороны, как господство над миром с помощью обретаемых магических сил-с другой $[2$, с. 311].

Есть и другая, для Вебера не менее важная дихотомия: ним выделяется аскеза рациональная и иррациональная; в пределах христианства 
эта дихотомия совпадает с разделением, соответственно, на западную и восточную школы аскетизма. Установка рациональности принципиальна и усиленно подчеркивается: именно она служит переходным звеном, за счет которого религиозные установки постепенно переводятся в установки социально-экономического поведения. В сочинении «Протестантская этика и дух капитализма» Вебер отмечал:

Христианская аскеза [...] на Западе в ее наиболее разработанных формах уже в Средние века, а подчас и в античности, носила рациональный характер. [...] Она превратилась в систематически разработанный метод рационального жизненного поведения, целью которого было преодоление status naturae, освобождение человека от иррациональных инстинктов, от влияния природы и мира вещей и подчинение его жизни некоему планомерному стремлению, а его действий - постоянному самоконтролю и проверке их этической значимости [...] Подобное активное самообладание было [.. ] целью ехеrcitia св. Игнатия и высших форм рациональной монашеской добродетели вообще, как и основным идеалом практической жизни пуритан [...] Целью аскезы было создать условия для деятельной, осмысленной, светлой жизни; ее настоятельной задачей - уничтожить непосредственное чувственное наслаждение жизнью; ее главным средством - упорядочить образ жизни [2, с. 154-155].

Отличительной особенностью западного христианства является понимание христианизации как перехода от естественного к социальному, от природы к культуре. Чем больше взаимосвязей между людьми, тем больше запретов на импульсивные проявления человеческой природы, тем больше дистанции по отношению к телу. Подчинение чувственности духовному идеалу, руководство чувственностью со стороны церкви было продуманной стратегией католической церкви. Вебера интересует эта продуманная рациональность, целенаправленность в стратегиях сознания и поведения, подчинение существования человека началам порядка, метода. Мы убеждаемся в том, как активно протестантизм оперирует социальными характеристиками индивида, в сколь большей степени апеллирует к его культурным, а не естественным, природным определениям.

Отличие кальвинистской аскезы от средневековой (западно-католической), очевидно в отказе от Евангельских советов и в преобразовании тем самым аскезы в чисто мирскую аскезу [там же, с. 156].

Сутью обмирщения аскезы стало убеждение в том, что можно и без Церкви обрести спасение и святость. Модернизация, сопровождаемая секуляризацией, привела к тому, что Церковь, благодать, исповедь как 
средства спасения потеряли свою сакральность, перестали быть таинствами.

Фактически тут закладывается механизм на замыкании человека в себе самом, в своей индивидуальности:

Пуританская аскеза, как и любая другая «рациональная» аскеза, стремилась научить человека руководствоваться «константными мотивами», а не «аффектами» [там же, с. 155].

«Религию спасения» Вебер рассматривает как наследницу пророческих движений и считает, что со временем она приобретала этические формы: «принимала облик рациональной этики, ориентированной на внутренние религиозные ценности, как средства спасения» [там же, c. 312]. Далее, по аналогии с Фрейдом, он применяет понятие сублимации, но уже в своей сфере:

Чем больше она («религия спасения»), сублимируясь, переходила от ритуализма к «религии, основанной на внутренней убежденности», [...] тем сильнее росла сознательная рационализация и сублимирование отношения людей к различным сферам владения внешними и внутренними религиозными и мирскими благами $[\ldots]$ это приводит к осознанию внутренней закономерности. Это общее и чрезвычайно важное для истории религии следствие [там же, с. 312-313].

Фактически, в этой цитате Вебер показывает закономерный переход от христианства к рациональной этике. Рационализация христианской веры приводит к росту уверенности человека по поводу своего спасения.

Тем самым «религия спасения» превращалась в деловое предприятие:

Пуритане позднего времени контролировали не только свое поведение, но и Бога. Они совершенно точно знали, почему Бог принял то или иное решение. Следствием подобной методичности в этическом поведении $[\ldots]$ была глубокая христианизация всего человеческого существа [там же, с. 160].

То есть в методически рационализированном этическом поведении и состояла «религия спасения» и задача жизни человека была научиться этой методике.

Как справедливо отмечает Д.И. Полывянный, согласно гипотезе Вебера:

Принципы протестантской хозяйственной этики не изменили жизнь целых народов автоматически, они вначале привели к формированию 
элиты «религиозных виртуозов», которые смогли сделать эти ценности стержнем этического комплекса, разделяемого людьми разных сословий и занятий. Именно усилиями этих людей был сформирован «дух» общества, обеспечивший ему импульс к экономическому развитию [11, с. 360].

Интересно выяснить, насколько адекватной является веберовская методология для исследования других религий, в частности православия. Не являются ли выводы исследователя ошибочными, поскольку он опирался на узкую географическую основу (Европа, США)?

В предисловии к украинскому переводу книги канадского философа Чарльза Тейлора «A Secular Age» ${ }^{1}$, в которой подробно анализируются изменения в европейском обществе и культурном сознании XVI-XX ст., помещено слово к украинскому читателю. Автор предполагает, что пути модернизации в разных цивилизациях мира различны. В траектории «секуляризации» также можно обнаружить отличия от западного контекста. Мир греческого православия - это другой цивилизационный контекст, что надо учитывать для понимания больших изменений, которые произошли и продолжают происходить в религиозной жизни Европы. Тейлор отмечает, что латиняне и греки сформировали две разные христианские цивилизации, которые мы называем «христианствами», каждая с родственным, но отличным богословским видением, и что важнее, с разными побуждениями к Реформе [12, с. 9]. Тейлор убежден, что сравнение цивилизаций - это путь к самим себе.

Вебер это тоже учитывал. Правда, православие заинтересовало исследователя на относительно короткий срок в начале 1900-х гг. в контексте его работы над «Хозяйственной этикой мировых религий», причем на фоне его интереса к буддизму, конфуцианству или даже индуизму, внимание, которое ученый уделил православной тематике, было очень ограниченным [16]. Православие интересовало его прежде всего с точки зрения особенностей общества современной ему России (см.: [3]). Профессор сравнительной социологии Андреас Бусс отмечает, что трактовка Вебером православия похожа на ту, что дал русский философ В.С. Соловьев в «Рассказе об Антихристе».

Вебер пришел к выводу, что православие производит человека мирской аскезы. Представления о необходимости и возможности выполнения аскетических обетов в мирской жизни присутствовали в православии всегда, с момента возникновения. Сам Христос уединялся в пустыню и другие уединенные места для личной молитвы. Аскетическая

\footnotetext{
${ }^{1}$ Вышел первый том, который содержит первую-третью части оригинального труда Тейлора.
} 
практика способствовала появлению многих монастырей и подвижников: уже в IV в. монахи строят в монастырях новое общество, новый социальный организм. Этот новообразованный социум недолго пребывал в отрыве от мира. Та аскетическая практика, которая сформировалась в пустынях и монастырях, находила широкий отклик в миру. Представления о возможном достижении идеала обожения не только в монастыре, но и в миру, привели к разработке Григорием Паламой в XIV в. концепции, согласно которой мирская жизнь совместима с аскетической практикой.

В связи с задачами статьи остановимся на мало проанализированной в литературе работе Зильбермана «Православная этика и материя коммунизма», опубликованной в США в 1977 году, где сравниваются восточные и западные христианские религиозные традиции.

Зильберман знал о критике Вебера, о его главной методологической трудности - представив протестантизм чем-то исключительным, он сделал его мерой присутствия религии в современности [8, с.33]. По мнению Зильбермана, тем самым веберовская традиция попала в замкнутый круг. Начались поиски в иных цивилизациях религиозных течений, движущихся к протестантскому идеалу или удаляющихся от него. При этом предполагалось, что развитие религии в направлении протестантизма создавало условия для развития экономики в сторону капитализма. Однако чистый эксперимент здесь невозможен: все современные общества в той или иной мере подверглись воздействию капитализма, и потому нельзя установить, привело бы их независимое развитие к какому-либо иному итогу. Нельзя строго проследить влияние религиозных факторов на ход истории. Но Зильберман предложил выход из этого замкнутого круга. Он сосредоточил внимание на анализе механизмов, действующих в различных типах культурной традиции, которые ведут к созданию самих этих типов.

Логика здесь ровно та же, что и у Вебера: религиозные традиции оказывают влияние на социальную организацию и социальную активность даже в секуляризированных обществах. Но Зильберман идет дальше Вебера и берет во внимание разные типы культурной традиции, типы рациональности и ставит проблему различных целей в историческом развитии. Он ищет нечто отличное от «протестантского» типа ценностной ориентации и при этом не менее весомое и значительное. Такой альтернативой стала русская религиозная традиция, с ее типичными комплексами: «Страха Божия», «Страшного суда».

Я начал с анализа наследия тех византийских богословов, чье воздействие на русскую ментальность оказалось самым значительным 
(святой Симеон, святой Максим Исповедник, святой Григорий Палама). Могу поручиться, что некоторые фрагменты их реформ выглядят как самые новейшие инструкции относительно того, как иметь дело с инакомыслием, с проблемой передела власти, моральным вознаграждением и т.п. $[8$, с. 15$]$.

Исследование «внутреннего смысла» российской культуры, тесно связанной с православием, привело Зильбермана к выводу о том, что сутью православия является «деятельный активизм». Россия стала наследницей византийской ментальности активизма. В то время как вся западная цивилизация выстраивается у него из западного мистического опыта, который оценивается как пассивный:

Подобного рода мистицизм был не деятельностью, а лишь описанием задним числом того, что произошло с субъектом [там же, с. 88].

Проследим, каким путем Зильберман получил этот вывод. Рассматривая восточное и западное христианство, выделяя особенность их богословия и философии, Зильберман сосредоточился на религиозном опыте, на котором основывались культурные традиции различных цивилизаций. И в этой связи на первый план в его анализе выходит аскеза. Он рассматривает аскезу, называя мистиков «духовными атлетами». Но деятельность этих «атлетов» различна в разных исторических традициях. По его мнению, западный мистицизм «экстатичен», основан на ожидании дара свыше, на ощущении озарения.

Зильберман достаточно четко улавливает стратегию восточного христианства (на примере византийского православия), состоящую в том, что спасение человека возможно только во взаимной «синергии» Бога и человека. Он обращается к Максиму Исповеднику, как одному из первых разработчиков этого богословского утверждения:

Бог нуждается в человеческой «синергии», чтобы стать Богом живым. Максим провозгласил это фундаментальным принципом православия. Две природы не могут иметь одну волю и если конкретный человек не может достичь теозиса усилиями собственной воли, то Бог тоже не может воскресить его [там же, с. 115].

«Деятельный активизм» православия выражается в двух важных положениях, которые связаны в свою очередь с обоснованием христоцентризма: (1) аскетизм рекомендуется не только монашествующим, но и всем остальным как общеобязательная практика, так как каждый человек призван к обожению; (2) важная роль в аскетической практике отводится свободной воле человека. Воля - это свойство личности, 
деятельная сила души, отвечающая за потребность к действию, побуждаемая чувством и руководимая разумом, это способность принять решение. Согласование человеческой и Божественной воли ведет человека к обожению. Волевая деятельность «есть деятельность разумная» (св. Иоанн Дамаскин), поэтому воля и сознание тесно сотрудничают в православной аскетике. Так как новый подход Максима Исповедника отрицал «космические» и «мифологические» аспекты христианства и настаивал на историчности встречи отдельных избранных людей с Живым Богом, он может быть определен как реставрация идеи пророков и духа Ветхого Завета [там же, с. 119].

Обращаясь к теме греха, преступления и Царствия Божия, Зильберман разделяет видение этих понятий между восточной и западной традицией. Для католиков Царствие Божие все-таки «на небе» и именно в этой мысли и состоит радикальное отличие Востока от Запада:

Здесь проходил великий водораздел мысли [...] противоположный взгляд символа нематериального или недейственного или просто описательного превалировал на Западе, прошел через Реформацию и выразился в сегодняшнем мире конвенциональном и релятивистском, где материальное и духовное отделены друг от друга. Творение было заклеймено «тварным» и тем самым подверженным вине и греху [там же, с. 137].

По мнению исследователя, противоречие между творением и тварным, грехом и виновностью привело к Реформации, которая отвергла благодать, сводя ее к «индексу» веры. Этот «индекс» веры использовался как «напоминание верить в обещанное Евангелие или как чувство вины за отсутствие веры. Сущность и действие благодати забыты и лишены реальности» [там же, с. 137].

Подведем итоги. В рассмотренных нами двух теориях религиозные традиции рассматриваются не в старой манере как идеологии, уничтожающие свободу человека и принижающие его. Они интерпретируются как способы порождения значений, оказывающие влияние на способы осуществления социального действия.

Разговор об аскетике сразу же погружает нас в мир человеческой активности, практик, направленных на переориентацию воли человека. В рамках веберовского подхода аскетизм рассматривается как основной двигатель процесса рационализации отношения к миру и формированию современных структур сознания.

Во второй половине ХХ века пересматриваются отдельные положения веберовской теории. На примере философии Зильбермана можно 
заключить, что это осуществляется за счет введения понятия «культурное различие», перехода от логического универсализма к логикам как системам, множество которых формируется на различии первоначальных посылок (аксиоматик) [там же, с. 186]. Предметом философии становится не «натуральный объект», а построение высказываний, формирование деятельности, способы установления объектов и их отношений. Разрабатывая разные культурные реальности, неклассическое мышление признает онтологическую неполноту каждой из них. Отсюда по-иному мыслится субъективность. Но неполнота и различия придают субъекту деятельный статус. Субъект перестает мыслиться как созерцатель или исследователь заранее заданной реальности. Теперь он включен в процесс производства своей реальности.

Надо сказать, что процесс создания субъективности в православной традиции оказывается более отвечающим современному миропониманию, чем в западном христианстве. В православии человек принимает позицию незавершенной истории и себя как ее деятеля-субъекта. В религиозной интерпретации он становится со-работником Бога в построении его царства на земле, что было сформулировано монашеской традицией как «духовный атлетизм».

Концептуальное осмысление аскетики и духовных практик означает попытку применения рационально-научного стиля к антрополого-экзистенциальной составляющей. На наш взгляд, на современном этапе изучения религий это необходимо, чтобы раскрыть сущностные характеристики основных религиозных понятий.

\section{Литература}

[1] Бибихин В.В. Другое начало. - СПб. : Наука, 2003.

[2] Вебер М. Избранные произведения. - М. : Прогресс, 1990.

[3] Вебер М. О России. - М. : РОССПЭН, 2007.

[4] Гайденко П.П., Давыдов Ю.Н. История и рациональность: Социология М. Вебера и веберовский ренессанс. - М. : Политиздат, 1991.

[5] Гнатенко Е.А. Философский проект правового государства в культуре предреволюционной России. Монография / МВД Украины, Луган. акад. внутр. дел им. 10-летия независимости Украины; [Научн. ред. К.В. Деревянко]. - Луганск : РИО ЛАВД, 2003. 
[6] Делез Ж. Переговоры. - СПб. : Наука, 2004.

[7] Дмитриев М.В. Человек православный и Homo Catholicus // Интеллектуальный форум. - 2002. - № 9. - С. 63-87.

[8] Зильберман Д. Православная этика и материя коммунизма. СПб. : Изд-во Ивана Лимбаха, 2014.

[9] Kаллист (Уэр), митрополит. Путь аскетов: отрицание или утверждение? [Электронный ресурс].-Режим доступа: http://azbyka.ru/otechnik/Kallist_Uer/put-asketov-otritsanieili-utverzhdenie/

[10] Корзо М. Образ человека в проповеди XVII века. - М. : ИФРАН, 1999.

[11] Полывянный Д.И. Макс Вебер о православии и его влиянии на общественно-политическое развитие России // Сравнительное изучение религиозных традиций: Россия, Восточная Европа, постсоветское пространство. - Иваново: Ивановский государственный университет, 2010. - С. 353-365.

[12] Тейлор Ч. Секулярна доба. Книга перша. - К. : Дух і Літера, 2013.

[13] Узланер Д.А Становление неоклассической модели секуляризации в западной социологии религии второй половины XX в. // Религиоведение. - 2008. - № 2. - С. 135-148.

[14] Фуко М. Герменевтика субъекта. Курс лекций, прочитанных в Колледже де Франс в 1981-1982 уч. году. - СПб. : Наука, 2007.

[15] Хоружий С.С. Фонарь Диогена.-M. : Прогресс-Традиция, 2010.

[16] Buss A. Russian Orthodox Tradition and Modernity. - LeidenBoston: Brill, 2003.

Надійшла до редакиї 08 січня 2016 р. 


\section{Анотація}

Куценко В.Ю. Аскетика як предмет філософського осмислення

У статті розглядається аскетика як можливий механізм конструювання суб’єктності. Автор вважає, що спроби філософської інтерпретації аскетики в роботах М. Вебера і Д. Зільбермана в якості основного двигуна процесу раціоналізації ставлення до світу і формування сучасних структур свідомості не втратили своєї актуальності.

Ключові слова: аскетика, суб’єктність, релігійна свідомість, аскетичні практики, раціональність.

\section{Abstract}

Kutsenko V.Y. Asceticism as an object of philosophical reflection

The article considers asceticism as a possible mechanism for the construction of subjectivity. The author claims that philosophical interpretations of asceticism by Max Weber and David Zilberman as the main engine of the streamlining relationship to the world and the formation of modern structures of consciousness remain highly relevant and require further development.

Keywords: Asceticism; subjectivity; religious consciousness; ascetic practices; rationality.

\section{References}

1. Bibihin V.V. Drugoe nachalo. — SPb. : Nauka, 2003.

2. Weber M. Izbrannye proizvedeniya. — Moscow : Progress, 1990.

3. Weber M. O Rossii. - Moscow : ROSSPEHN, 2007.

4. Gajdenko P.P., Davydov YU.N. Istoriya i racionalnost: Sociologiya M. Vebera i veberovskij renessans. — Moscow : Politizdat, 1991.

5. Gnatenko E.A. Filosofskij proekt pravovogo gosudarstva v kulture predrevolyucionnoj Rossii. Monografiya / MVD Ukrainy, Lugan. akad. vnutr. 
del im. 10-letiya nezavisimosti Ukrainy; [Nauchn. red. K.V. Derevyanko]. — Lugansk : RIO LAVD, 2003.

6. Deleuze G. Peregovory. — SPb. : Nauka, 2004.

7. Dmitriev M.V. CHelovek pravoslavnyj i Homo Catholicus // Intellektualnyj forum. - 2002. — № 9. - S. 63-87.

8. Zilberman D. Pravoslavnaya ehtika i materiya kommunizma. — SPb. : Izdvo Ivana Limbaha, 2014.

9. Kallist (Uehr), mitropolit. Put asketov: otricanie ili utverzhdenie? : http://azbyka.ru/otechnik/Kallist_Uer/put-asketov-otritsanieili-utverzhdenie/

10. Korzo M. Obraz cheloveka v propovedi HVII veka. - Moscow : IFRAN, 1999.

11. Polyvyannyj D.I. Maks Veber o pravoslavii i ego vliyanii na obshchestvennopoliticheskoe razvitie Rossii // Sravnitel'noe izuchenie religioznyh tradicij: Rossiya, Vostochnaya Evropa, postsovetskoe prostranstvo. - Ivanovo: Ivanovskij gosudarstvennyj universitet, 2010. — C. 353-365.

12. Teylor C. Sekulyarna doba. Knyga persha. - K. : Duh i Litera, 2013.

13. Uzlaner D.A Stanovlenie neoklassicheskoj modeli sekulyarizacii v zapadnoj sociologii religii vtoroj poloviny XX v. // Religiovedenie. — 2008. — № 2. - S. 135-148.

14. Foucault M. Germenevtika sub"ekta. Kurs lekcij, prochitannyh v Kolledzhe de Frans v 1981-1982 uch. godu. — SPb. : Nauka, 2007.

15. Horuzhij S.S. Fonar Diogena. — Moscow : Progress-Tradiciya, 2010.

16. Buss A. Russian Orthodox Tradition and Modernity. — LeidenBoston : Brill, 2003. 